\title{
Molecular Diversity of the Calcium Channel $\alpha_{2} \delta$ Subunit
}

\author{
Norbert Klugbauer, Lubica Lacinová, Elsé Marais, Muriel Hobom, and Franz Hofmann \\ Institut für Pharmakologie und Toxikologie der Technischen Universität München, 80802 München, Germany
}

\begin{abstract}
Sequence database searches with the $\alpha_{2} \delta$ subunit as probe led to the identification of two new genes encoding proteins with the essential properties of this calcium channel subunit. Primary structure comparisons revealed that the novel $\alpha_{2} \delta-2$ and $\alpha_{2} \delta-3$ subunits share 55.6 and $30.3 \%$ identity with the $\alpha_{2} \delta-1$ subunit, respectively. The number of putative glycosylation sites and cysteine residues, hydropathicity profiles, and electrophysiological character of the $\alpha_{2} \delta-3$ subunit indicates that these proteins are functional calcium channel subunits. Coexpression of $\alpha_{2} \delta$-3 with $\alpha_{1 C}$ and cardiac $\beta 2$ a or $\alpha_{1 E}$ and $\beta 3$ subunits shifted the voltage dependence of channel activation and inactivation in a hyperpolarizing direction and accelerated
\end{abstract}

Voltage-gated calcium channels have been purified and cloned from various tissues such as skeletal muscle, heart, and brain. These channels are formed by heterooligomeric complexes consisting of various combinations of an $\alpha_{1}$ protein with auxiliary $\alpha_{2} \delta, \beta$, and $\gamma$ subunits. To date, seven genes encoding $\alpha_{1}$ subunits of the high voltage-activated (for review, see Hofmann et al., 1994; Strom et al., 1998; Bech-Hansen et al., 1998) and two genes of the low voltage-activated calcium channels have been identified (Perez-Reyes et al., 1998; Cribbs et al., 1998). This subunit accounts not only for the ion channel pore but also contains the voltage sensor and the determinants for binding of drugs and toxins. The current through the $\alpha_{1}$ subunit is modulated by interactions with the $\beta, \alpha_{2} \delta$, and $\gamma$ subunits. The molecular diversity of the $\beta$ subunit is not only caused by the expression of four genes, but also by differential splicing. Until recently, only a single $\gamma$ subunit in skeletal muscle had been described (Eberst et al., 1997), but a novel neuronal form has since been identified in brain (Letts et al., 1998).

Since the molecular cloning of the $\alpha_{2} \delta$ subunit (Ellis et al., 1988), several splice variants have been detected, but no further $\alpha_{2} \delta$ subunit genes have been identified. The different splice variants arise from various combinations of three alternatively spliced regions that result in five isoforms that are expressed in a tissuespecific manner (Angelotti and Hofmann, 1996). Structurally, the $\alpha_{2} \delta$ subunit is a heavily glycosylated $175 \mathrm{kDa}$ protein that is posttranslationally cleaved to yield a disulfide-linked $\alpha_{2}$ and $\delta$ protein (DeJongh et al., 1990; Jay et al., 1991). The $\delta$ part anchors the $\alpha_{2}$ protein to the membrane via a single transmembrane

Received Sept. 14, 1998; revised Nov. 2, 1998; accepted Nov. 3, 1998.

This work was supported by the Deutsche Forschungsgemeinschaft and Fond der Chemie.

Correspondence should be addressed to Dr. Norbert Klugbauer, Institut für Pharmakologie und Toxikologie der Technischen Universität München, Biedersteiner Strasse 29, 80802 München, Germany.

Dr. Lacinová contributed to this paper while on leave from Institute of Molecular Physiology and Genetics, Slovak Academy of Sciences, Vlarska 5, 83304 Bratislava, Slovakia.

Copyright (ㄷ) 1999 Society for Neuroscience $\quad 0270-6474 / 99 / 190684-08 \$ 05.00 / 0$ the kinetics of current inactivation. The kinetics of current activation were altered only when $\alpha_{2} \delta-1$ or $\alpha_{2} \delta$-3 was expressed with $\alpha_{1 \mathrm{C}}$. The effects of $\alpha_{2} \delta-3$ on $\alpha_{1 \mathrm{C}}$ but not $\alpha_{1 \mathrm{E}}$ are indistinguishable from the effects of $\alpha_{2} \delta-1$. Using Northern blot analysis, it was shown that $\alpha_{2} \delta-3$ is expressed exclusively in brain, whereas $\alpha_{2} \delta-2$ is found in several tissues. In situ hybridization of mouse brain sections showed mRNA expression of $\alpha_{2} \delta-1$ and $\alpha_{2} \delta-3$ in the hippocampus, cerebellum, and cortex, with $\alpha_{2} \delta-1$ strongly detected in the olfactory bulb and $\alpha_{2} \delta-3$ in the caudate putamen.

Key words: $\alpha_{2} \delta$ subunit; voltage-activated channel; calcium channel subunit; neuron; gene diversity; electrophysiology segment (Gurnett et al., 1996). The membrane topology of the $\alpha_{2} \delta$ subunit was further refined using anti- $\alpha_{2}$ antibodies and C-terminal deletion mutants (Brickley et al., 1995; Wiser at al., 1996). Structural studies have shown that the extracellular $\alpha_{2}$ domain provides the structural elements required for channel stimulation (Gurnett et al., 1996) and that the $\delta$ domain, which contains the only transmembrane segment of $\alpha_{2} \delta$ complex, harbors the regions important for the shift in voltage-dependent activation, steady-state inactivation, and the modulation of the inactivation kinetics (Felix et al., 1997). The identification of new $\alpha_{2} \delta$ subunits could present further possibilities for differential and specific regulation of calcium channels.

In studies designed to address the diversity and function of $\alpha_{2} \delta$, cloning, hybridization, and patch-clamp techniques were used to identify and characterize novel $\alpha_{2} \delta$ subunits. Two new $\alpha_{2} \delta$ genes were found by searching databases with the $\alpha_{2} \delta$ cDNA sequence (Ellis et al., 1988). These genes encode proteins with essential features of $\alpha_{2} \delta$ subunits, such as the high number of potential glycosylation sites and cysteine residues, the hydrophobicity plots, and electrophysiological characteristics. The novel $\alpha_{2} \delta-2$ gene was found to be predominately expressed in heart, pancreas, and skeletal muscle, with $\alpha_{2} \delta-3$ expressed only in brain.

\section{MATERIALS AND METHODS}

Isolation of RNA and cDNA library construction. Total RNA from mouse brain was isolated by the guanidinium thiocyanate method, and the poly(A) RNA was separated by oligo-dT cellulose chromatography (Poly(A) Quik mRNA Isolation kit; Stratagene, Heidelberg, Germany). Poly(A) RNA from mouse brain was reverse-transcribed, and doublestrand cDNA was synthesized using the Superscript plasmid system (Life Technologies). The cDNA fragments were ligated with BstXI/EcoRI adaptors (Invitrogen, San Diego, CA) and size-fractionated in a lowmelting agarose gel. Only gel slices containing fragments $>2000 \mathrm{bp}$ were excised and digested with Gelase (Biozym, Hessisch Oldendorf, Germany). Recovered cDNA was ligated into the BstXI site of the pcDNAII vector (Invitrogen) and transformed in the Escherichia coli XL1-blue mrf' strain (Stratagene, Heidelberg, Germany). The cDNA library was screened with a random-primed labeled PCR probe (see below, nt 1501-1821). Sequencing of the clones was performed using the dideoxy 


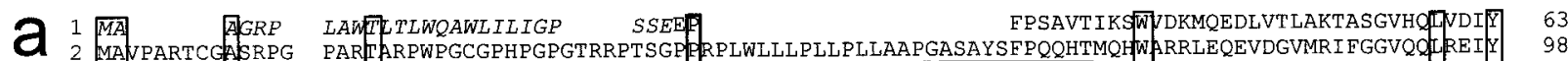

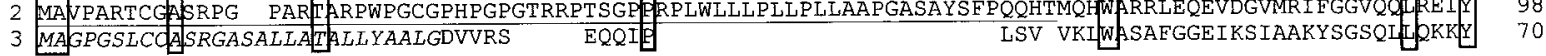

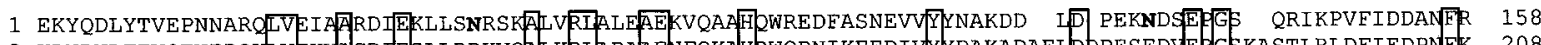

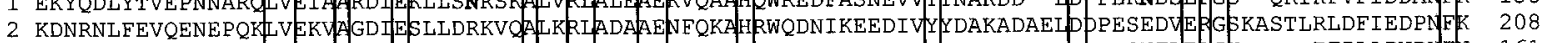

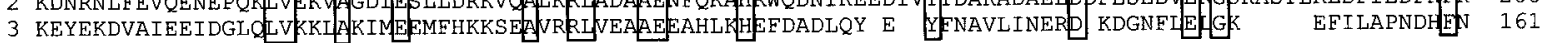

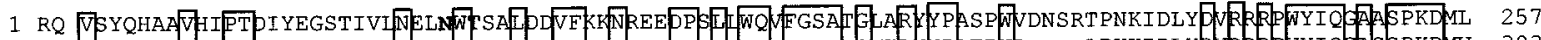

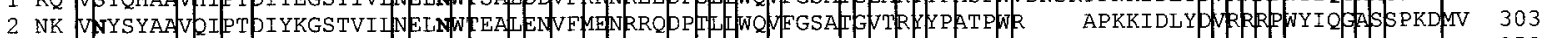

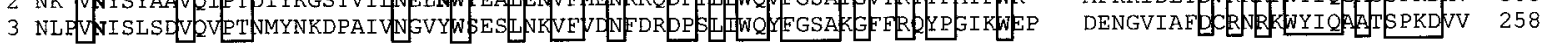

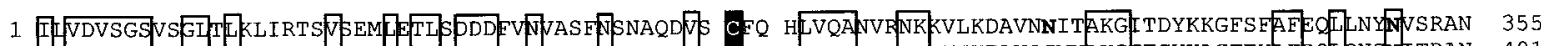

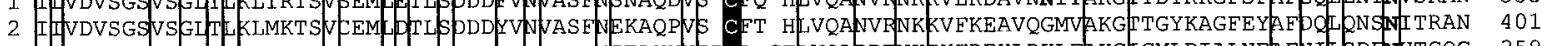

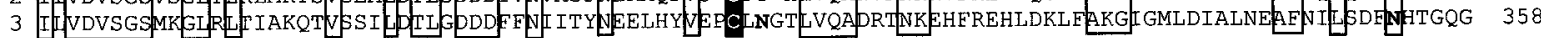

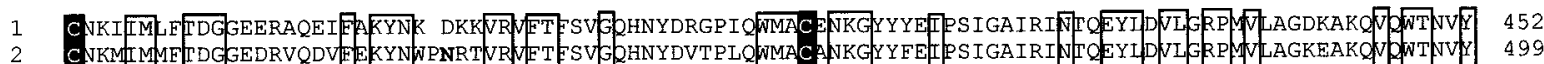

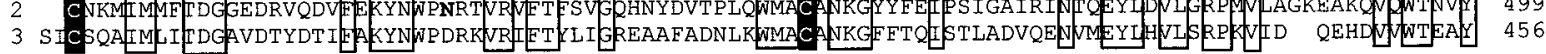

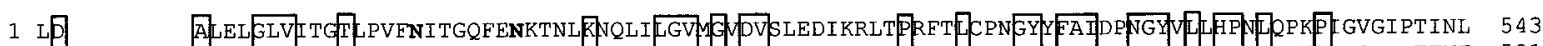

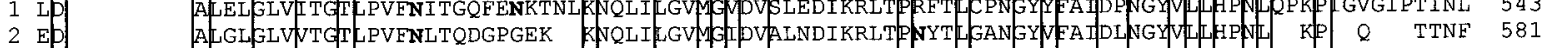

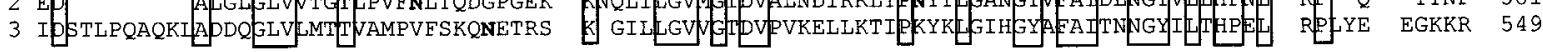

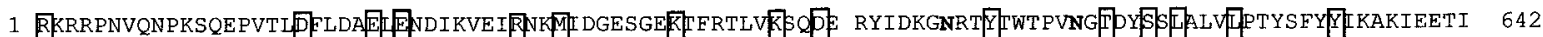

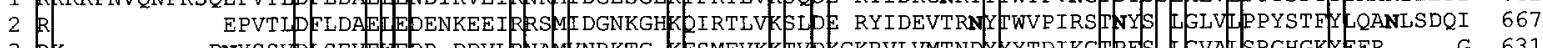

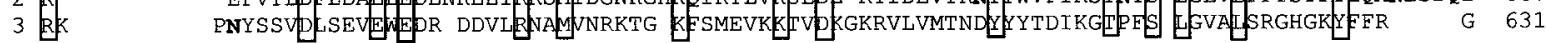

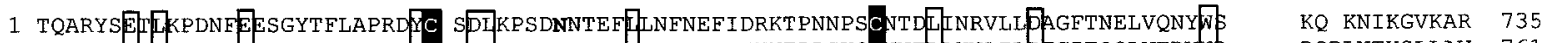
2 LQVKYEEEEL LPSSEESEGHVFIAPRE IC KDLNASDNNTEE KNFIELMEKVTPDSKOC NNFLEHNLILEFGITQOLVERVNR DQDLNTYSLLAV 761

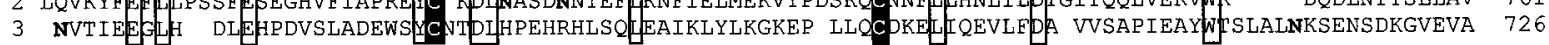

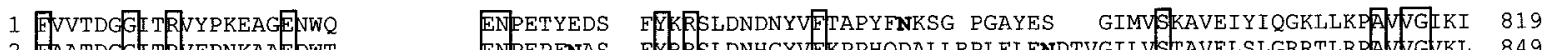
2 AAATDGG TENFPNKAAEDWT ENPEPFNAS FMRRSLDNHGYVEKPPHODALLRPLELENDTVGILVSTIAVELSLGRRTLRPAWVGNKL 849 3 ELGTRTGS ENLFVGAELTNQDFLKAGDRENHFNADHFPLWWRAAEQIAGSEVYSIPFSTG TVNKSN VVTASISIQLLDERKSPVVAAVGIQM 822

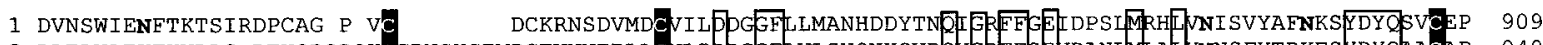

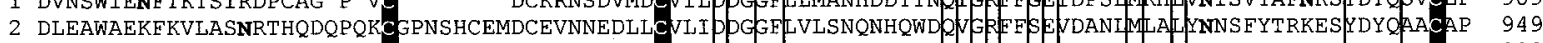

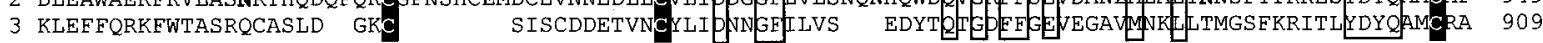
1 GAAPKQGAGHRSAYVPSIADI周QIGWW WTAAAWS ILQQFLLSLTEPRLLFA ADMEDDDFTASMSKQS 2 OPPGNLGAAPRGVFVPTVADFU NLAWWTSAAAWSLFOQLLYGIIYSFEADPAEAEGSPETR ESSC NMKQTQYYFGSVNASYNAIIDCGNCSRLPHAQ 1048 3 N KESSDSAHGLLDPYKAE UAAKNIMTELVLFLVEFNLCSWWHSDMTAKAQK LKQTLEPCPTEYPAFVSERTIKETTGNIACEDCSKSEVIQ 1001

1 KLMNTNLTFIMVESKGTCPCDTRLLIQAEQTS DGPDPCDMVKQPRYFKGPDVCFDNNVLEPYTDCGGVSGLNPSLWSIIGIQFVLFWLVSG SRHCL 1105 2 RLTNTNLLFVVAEKPLCSOCEAGRLLQKETHCPADGPEQCELVQRPRY RRGPHICFDYNATEDTSDCGRGASFPPSLGVLVSLQLLLELGLPPRPQPQVL 1148 3 QIPSSUTIFMVVDSSCLCESVAPITMAPIEIR YNESLKCERLKAQKIERRPESCHGFHPE ENARECGSASSLQAQAALLLLPLVSSGESR 1091

$1 \mathrm{~L} \quad 1106$

2 VHASRRL 1155

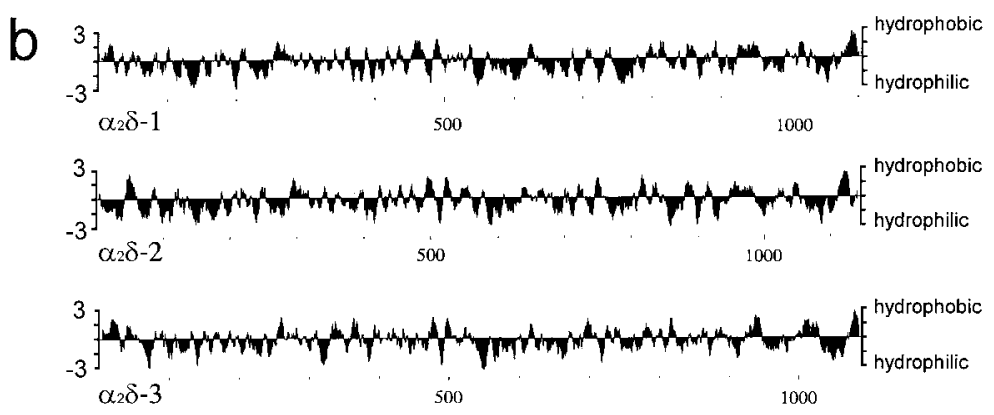

Figure 1. a, Amino acid alignment of the $\alpha_{2} \delta-1$ (1), $\alpha_{2} \delta-2$ (2), and $\alpha_{2} \delta-3$ (3) subunits. The N-terminal region differing between the $\alpha_{2} \delta$ - 2 subunit isoform I and II is underlined. Regions that are identical in all sequences are boxed, and conserved cysteine residues are additionally highlighted. The presumptive signal peptides for classes 1 and 3 are shown in italics. Potential $N$-glycosylation sites are printed in bold. The arrow indicates the cleavage site between the $\alpha_{2}$ and $\delta$ proteins of the $\alpha_{2} \delta$-1 subunit. These sequence data are available from the EMBL database under accession numbers M21948 for the $\alpha_{2} \delta$ - 1 subunit, AF042792 for the $\alpha_{2} \delta$-2(I) subunit, and AF042793 for the $\alpha_{2} \delta$-2(II) subunit isoforms, respectively, and AJ010949 for the $\alpha_{2} \delta$ - 3 subunit. $b$, Hydrophobicity profile of the $\alpha_{2} \delta$ subunits computed according to Kyte and Doolittle (1982). The curve is the average of a residue-specific hydrophobicity index over a window of nine residues. 
chain termination method on both strands. A full-length clone was used for the preparation of the NotI-SphI fragment with the entire open reading frame in pcDNA3 (Invitrogen) yielding the expression plasmid pc $3 \alpha_{2} \delta-3$.

PCR amplification. The expressed sequence tag (EST) with the accession number AA190607 was used to design the primers NKAD1, GGC ACA GAT GTC CCA GTT AAA GA and NKAD2, TGT ATA GTA GTA GTC ATT GGT CAT, with which the partial $\alpha_{2} \delta-3$ subunit cDNA was amplified. The PCR fragment was cloned in pUC18 and was sequenced on both strands.

Northern blot analysis. Human and mouse multiple tissue Northern Blots were obtained from Clontech (Heidelberg, Germany) and hybridized according to the manufacturer's instructions. Random-primed labeled fragments $\left(\alpha_{2} \delta-2\right.$, nt 2877-3249; $\alpha_{2} \delta-3$, nt 2893-3377) were used as probes; these regions share no significant homology with each other. A 3 hr prehybridization step was followed by an overnight hybridization with $5 \times 10^{6} \mathrm{cpm} / \mathrm{ml}$ of probe at $42^{\circ} \mathrm{C}$. The final stringency wash performed was with $0.1 \times \mathrm{SSC}, 0.1 \% \mathrm{SDS}$ at $42^{\circ} \mathrm{C}$

In situ hybridization. Intact brains of adult female mice were removed immediately after cervical dislocation and frozen in isopentane cooled to $-40^{\circ} \mathrm{C}$. Brain was sectioned into $16 \mu \mathrm{m}$ slices in a cryostat at $-20^{\circ} \mathrm{C}$ and thaw-mounted onto polylysine slides. The tissue was vacuum-dried, fixed in $4 \%$ paraformaldehyde in PBS, and washed in $0.5 \times$ SSC. The sections were acetylated in $0.25 \%$ acetanhydride in $0.1 \mathrm{M}$ triethanolamine, $\mathrm{pH} 8.0$, and washed in $2 \times$ SSC. The tissue was dehydrated through a series of ethanol solutions, from 50 to $100 \%$. The slides were vacuum-dried and stored at $-80^{\circ} \mathrm{C}$ until used.

Murine $\alpha_{2} \delta$-1 (nt 2760-3170), human $\alpha_{2} \delta$-2 (nt 2877-3249), and murine $\alpha_{2} \delta-3$ (nt 2744-3228) specific riboprobes were generated by in vitro transcription as described previously (Ludwig et al., 1997). Briefly, probe template DNA was amplified by PCR from murine $\alpha_{2} \delta-1$ and -2 clones using primers specific for the variable C-terminal region of $\alpha_{2}$. Bam HI and Asp 718 restriction sites were added to the $\alpha_{2} \delta$ - 1 forward and reverse primers, respectively, to allow for sticky-end ligation. $\alpha_{2} \delta-3$ was ligated to the linearized vector by blunt end ligation. The integrity of each probe was verified by dideoxy termination sequencing. ${ }^{35} \mathrm{~S}-\mathrm{UTP}$ (DuPont NEN, Wilmington, DE)-labeled sense and antisense riboprobes were generated using a standard T3 and T7 polymerase in vitro transcription procedure (T3 and T7 from New England Biolabs, Beverly, MA). Unincorporated nucleotides were removed using Sephadex G50 columns (Pharmacia, Freiburg, Germany).

Messenger RNA in situ hybridization was performed on cryostat sections of mouse brain. A prehybridization step was performed at $45^{\circ} \mathrm{C}$ for $2 \mathrm{hr}$. Hybridization with $1 \times 10^{7} \mathrm{cpm} / \mathrm{ml}$ probe proceeded for $16 \mathrm{hr}$ at $55^{\circ} \mathrm{C}$. After a $20 \mu \mathrm{g} / \mathrm{ml}$ RNase A (Boehringer Mannheim, Mannheim, Germany) digestion, a high-stringency wash of $0.1 \times \mathrm{SSC}, 1 \mathrm{~mm}$ EDTA, and $1 \mathrm{~mm}$ dithiothreitol was done for $2 \mathrm{hr}$ at $60^{\circ} \mathrm{C}$. The slides were dehydrated in ethanol and analyzed by autoradiography.

Transfection of HEK293 cells and electrophysiological recordings. The full-length cDNAs of all subunits, i.e., $\alpha_{1 \mathrm{C}}, \alpha_{1 \mathrm{E}}, \beta 2 \mathrm{a}, \beta 3, \alpha_{2} \delta \mathrm{a}-1$, and $\alpha_{2} \delta-3$ were cloned into the pcDNA 3 vector (Invitrogen). For more details, see Schuster et al. (1996). HEK 293 cells were transfected with various combinations of an $\alpha_{1}$ subunit $\left(\alpha_{1 \mathrm{C}}, \alpha_{1 \mathrm{E}}\right)$, a $\beta$ subunit $(\beta 2 \mathrm{a}, \beta 3)$, and an $\alpha_{2} \delta$ subunit $\left(\alpha_{2} \delta-1, \alpha_{2} \delta-3\right)$. This was achieved by lipofection with Lipofectamine (Life Technologies) at a DNA mass ratio of 1:1 for expression of two subunits or 1:1:1 for three subunits.

Electrophysiological recordings. Ionic currents from transfected cells were recorded in whole-cell configuration of the patch-clamp method. $\mathrm{Ba}^{2+}$ was used as the charge carrier. The extracellular solution contained (in mM): $N$-methyl-D-glucamine, $125 ; \mathrm{BaCl}_{2}, 20 ; \mathrm{CsCl}, 5 ; \mathrm{MgCl}_{2}, 1$; HEPES, 10; and glucose, 5, pH 7.4 ( $\mathrm{HCl})$. The intracellular solution contained (in mM): $\mathrm{CsCl}$, 60; $\mathrm{CaCl}_{2}$, 1; EGTA, 11; $\mathrm{MgCl}_{2}, 1 ; \mathrm{K}_{2} \mathrm{ATP}, 5$; HEPES, 10; and aspartic acid, 50, pH $7.4(\mathrm{CsOH})$. Currents were recorded using an EPC-9 patch-clamp amplifier and corresponding Pulse software from Heka Electronics (Lambrecht, Germany). Patch pipettes were pulled from borosilicate glass. The pipette input resistance was typically between 1.8 and $2.2 \mathrm{M} \Omega$. The capacity of individual cells ranged between 25 and $90 \mathrm{pF}$, and series resistance ranged between 3.5 and 5.0 $\mathrm{M} \Omega$. Capacity transients were compensated using build-in procedure of the Heka system. Curve fitting and statistical analysis were performed using the Origin 5.0 software package (Microcal, Northampton, MA). The significance of observed differences was evaluated by nonpaired Student's $t$ test. Probability of $5 \%$ or less was considered to be significant.

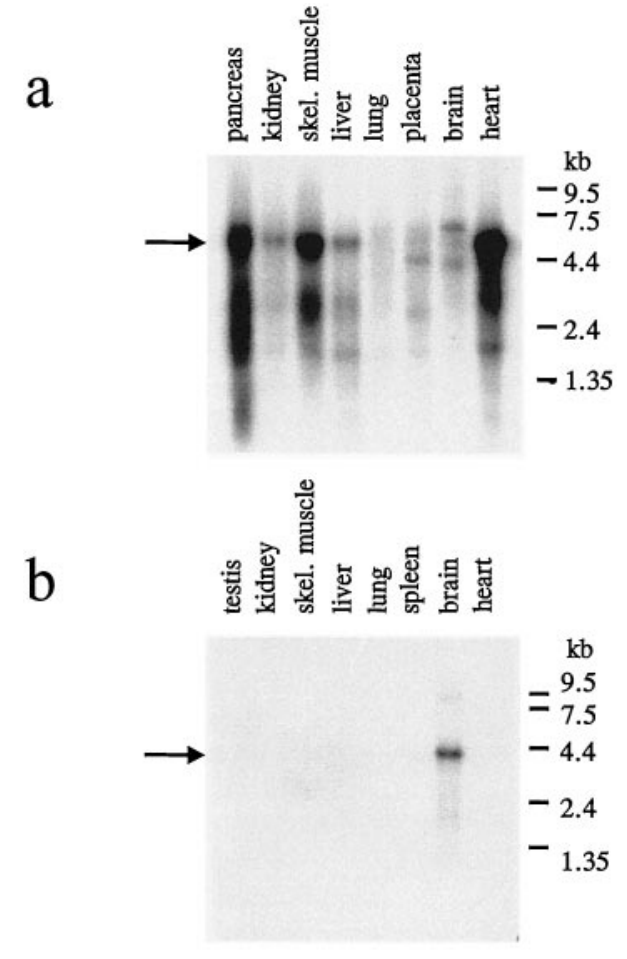

Figure 2. Northern blot analysis of the $\alpha_{2} \delta-2$ and $\alpha_{2} \delta-3$ subunits. For each lane, $\sim 2 \mu \mathrm{g}$ of poly(A) RNA was run on a denaturing formaldehydecontaining agarose gel, transferred to a nylon membrane, and fixed by UV irradiation. $a$, Human multiple tissue blot using a specific probe for the $\alpha_{2} \delta$-2 subunit. $b$, Mouse multiple tissue blot for the $\alpha_{2} \delta$-3 subunit. Arrows indicate predominant species of mRNA with sizes of $5.2\left(\alpha_{2} \delta-2\right)$ and 4.3 $\left(\alpha_{2} \delta-3\right) \mathrm{kb}$.

\section{RESULTS \\ Primary structures}

A database search using the $\alpha_{2} \delta$ subunit cDNA as probe revealed three additional sequences similar to this calcium channel subunit (Fig. 1), which were derived from two genes named 2 and 3. Two of these sequences are human full-length sequences of closely related isoforms of the $\alpha_{2} \delta$ subunit (GenBank accession numbers: AF042792, isoform I; AF042793, isoform II; M. H. Wei, F. Latif, F. M. Duh, D. Andreazzoli-Angeloni, V. Kashuba, E. Zabarovsky, B. Johnson, and M. I. Lerman, unpublished observations). These sequences differ only at the $\mathrm{N}$ terminus of the $\alpha_{2}$ protein, indicating that both isoforms are derived from the same gene 2 and are generated by differential splicing. The 5 '-untranslated region upstream of the ATG codon from isoform I is in good agreement with the Kozak sequence for initiation of translation in eukaryotic cells, whereas the same region of isoform II shows only a limited homology with this sequence. Furthermore, only isoform I but not isoform II shows features of a potential signal sequence. Both observations suggest that only isoform I can form a functional calcium channel subunit. Isoform I, which we describe here as the $\alpha_{2} \delta$-2 subunit, (Wei, Latif, Duh, Andreazzoli-Angeloni, Kashuba, Zabarovsky, Johnson, and Lerman, unpublished observations) has $55.6 \%$ identity with the $\alpha_{2} \delta-1$ subunit (Ellis et al., 1988). Eighteen potential $N$-glycosylation sites can be identified in the primary structure (Fig. 1), which is the same number of sites as in the $\alpha_{2} \delta-1$ subunit (Ellis et al., 1988).

The third sequence identified by database searches was a partial human EST sequence AC: AA190607. This sequence was 


$$
\alpha_{2} \delta-1
$$
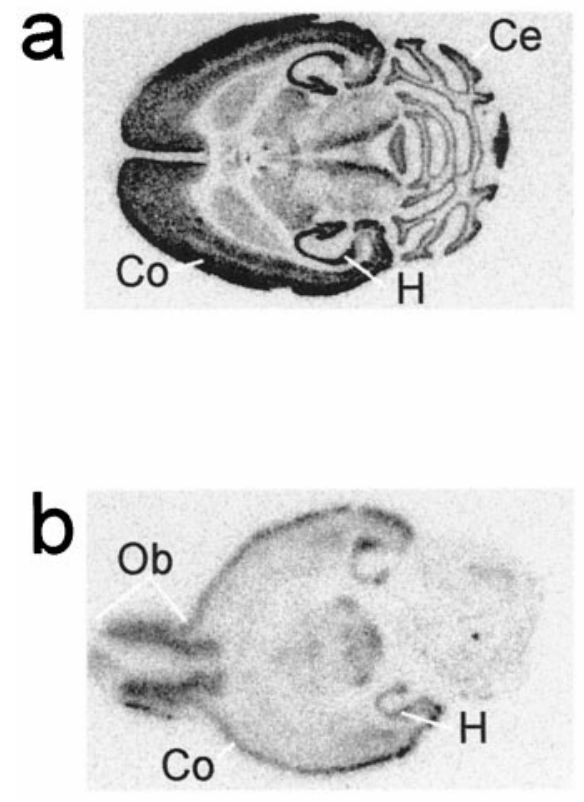

$\alpha_{2} \delta-3$
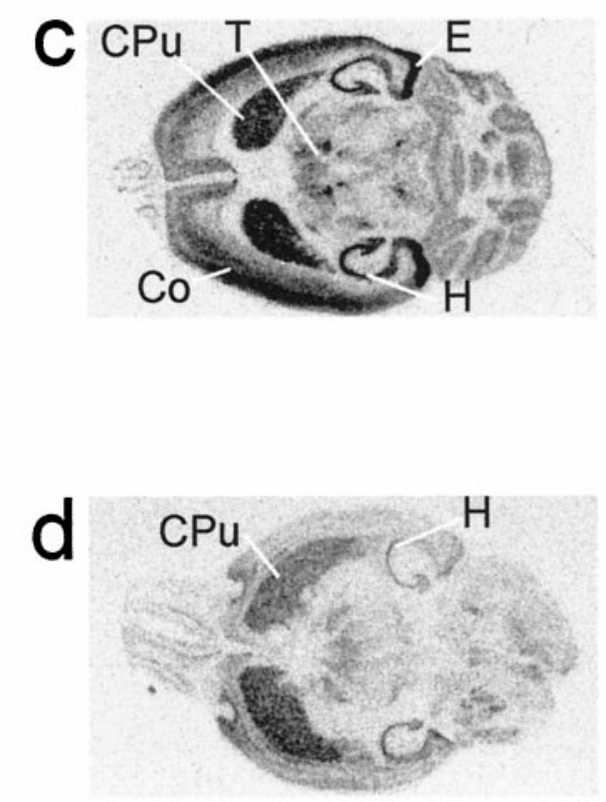

Figure 3. Autoradiographs of $\alpha_{2} \delta-1$ and $\alpha_{2} \delta-3$ riboprobe hybridization to horizontal mouse brain sections. Central ( $a$, $c)$ and more basal $(b, d)$ sections of the brain are shown. Expression of $\alpha_{2} \delta-1$ is seen in the $(a)$ hippocampus $(H)$, cerebral cortex $(\mathrm{Co})$, cerebellum $(\mathrm{Ce})$, and (b) olfactory bulb $(\mathrm{Ob}), \alpha_{2} \delta$-3 mRNA was detected in the caudate putamen $(C P u)$, hippocampus $(H)$, entorhinal complex $(E)$, cortex $(C o)$, and thalamic nuclei $(T)(c, d)$. used to design primers for the amplification of cDNA from mouse tissues. The cDNA could be amplified only from mouse brain mRNA and not from other tissues (Fig. 2). A cDNA library was constructed from mouse brain mRNA and screened with the PCR product as a probe. Several independent clones could be identified that encode the novel $\alpha_{2} \delta$ subunit, which we name $\alpha_{2} \delta-3$ (Fig. 1). A detailed restriction analysis of the different clones showed that there are no further isoforms in mouse brain. The sequence upstream of the start ATG is in agreement with that for the initiation of translation in eukaryotic cells (data not shown). The open reading frame consists of $3273 \mathrm{bp}$ encoding a protein with 1091 amino acid residues. The $\alpha_{2} \delta-3$ subunit has $30.3 \%$ identity with the $\alpha_{2} \delta-1$ subunit and $31.2 \%$ with the $\alpha_{2} \delta-2$ subunit. The primary structure of $\alpha_{2} \delta$-3 contains nine potential $N$-glycosylation sites (Fig. 1a).

Hydrophobicity analysis of all three $\alpha_{2} \delta$ subunits indicates a similar membrane topology, including a hydrophobic transmembrane segment at the $\mathrm{C}$ terminus of the $\delta$ domain (Fig. 1b). A sequence comparison reveals that as many as 14 cysteine residues are conserved in all of the three $\alpha_{2} \delta$ genes, further strengthening the postulate that these subunits are disulfide-linked proteins with similar higher order structures.

\section{Tissue distribution}

The expression of the novel $\alpha_{2} \delta$ subunits was examined by Northern and in situ hybridization. The $\alpha_{2} \delta-2$ subunit is highly expressed in heart, pancreas, and skeletal muscle tissue (Fig. 2), which can be seen even after $6 \mathrm{hr}$ of autoradiography of Northern blots. After $1 \mathrm{~d}$ of exposure, the $\alpha_{2} \delta-2$ subunit can also be detected in kidney, liver, placenta, and brain. This broad expression pattern was also observed for the $\alpha_{2} \delta$-1 subunit. An $8.0 \mathrm{~kb}$ transcript of the $\alpha_{2} \delta$-1 subunit was detected in brain, heart, aorta, skeletal muscle, and ileum (Ellis et al., 1988). In contrast to this ubiquitous expression pattern, the $\alpha_{2} \delta$-3 subunit is only found in brain (Fig. 2). In each case, the Northern analysis reveals one predominant species of mRNA with sizes of 5.2 (class 2) and 4.3 $\mathrm{kb}$ (class 3).

The mRNA expression of $\alpha_{2} \delta$-1 and $\alpha_{2} \delta$-3 calcium channel subunits in mouse brain was mapped by in situ hybridization. Both $\alpha_{2} \delta$ forms were detected in several regions of the brain, with differential expression of the mRNAs in some structures. Strong expression of $\alpha_{2} \delta$ - 1 was seen in the pyramidal cell layer of Ammon's horn in the hippocampus (CA1-3) and in the granular cell layer of the dentate gyrus (Fig. 3). The olfactory bulb also stained strongly, and expression in the mitral and glomerular cell regions was seen by dark-field microscopy of slides coated with photographic emulsion. Signals in the cerebellar cortex, and to a lesser extent in thalamic nuclei, were also observed (Fig. 3). Examination of emulsion-coated slides showed that the expression of $\alpha_{2} \delta$ - 1 in the cerebellum was restricted to the granular layer (data not shown).

The $\alpha_{2} \delta$-3 mRNA was predominantly expressed in the caudate putamen, entorhinal complex, hippocampus, and cortex (Fig. 3). As with $\alpha_{2} \delta$-1, the pyramidal cell layer of the hippocampus (CA1-3) and granular cell layer of the dentate gyrus showed the highest degree of hybridization with the antisense probe (Fig. 3). Hybridization of both probes was specific as judged by the absence of signals when sense probes were applied (data not shown). In situ hybridization for the $\alpha_{2} \delta-2$ subunit indicated a ubiquitous expression in cardiac tissues (data not shown).

\section{Functional characterization}

Because the Northern blot hybridization indicated a high expression of the $\alpha_{2} \delta-3$ subunit in brain, we performed cotransfection studies with $\alpha_{1}$ subunits that have been characterized in this tissue. Because in situ analysis did not show an exact colocalization of $\alpha_{2} \delta-3$ with known $\alpha_{1}$ subunits, coexpression studies were done with an $\alpha_{1}$ subunit of the dihydropyridine-sensitive class $\mathrm{C}$ 
and a dihydropyridine-insensitive class E calcium channel. This approach allows for the identification of interactions with both evolutionary distant calcium channel $\alpha_{1}$ families.

\section{Effects of the $\alpha_{2} \delta$-3 subunit on barium current through the $\alpha_{1 \mathrm{c}}$-type calcium channel}

To study the effects of $\alpha_{2} \delta$-3 subunit on channel gating, we coexpressed this subunit with the $\alpha_{1 \mathrm{C}}$ subunit alone or in combination with both $\alpha_{1 \mathrm{C}}$ and $\beta 2 \mathrm{a}$ subunits. Voltage protocols are described in detail in the legend to Figure 4, and quantitative analyses are summarized in Table 1 . When coexpressed with $\alpha_{1 \mathrm{C}}$ alone, the effects of $\alpha_{2} \delta-3$ on $\mathrm{I}_{\mathrm{Ba}}$ were less noticeable than when $\beta 2 \mathrm{a}$ was coexpressed. $\alpha_{2} \delta-3$ did not affect the current density, time course of current inactivation, and voltage dependence of steady-state inactivation of $\alpha_{1 \mathrm{C}}$ expressed singly (data not shown). However, when expressed with $\alpha_{1 \mathrm{C}}$ only, $\alpha_{2} \delta-3$ shifted the activation curve by $4.4 \mathrm{mV}$ in the hyperpolarizing direction and slightly accelerated the time of current activation during the depolarizing pulse (data not shown). The effects on the channel kinetics became more prominent in the presence of the $\beta 2 \mathrm{a}$ subunit (Fig. 4, Table 1). In this combination, $\alpha_{2} \delta-3$ significantly increased the current density, shifted the voltage dependence of current activation by $8.7 \mathrm{mV}$ in a hyperpolarizing direction, accelerated the time course of current activation during the depolarizing pulse, accelerated the current inactivation at positive membrane potentials, shifted the steady-state inactivation curve in a hyperpolarizing direction, and significantly changed its slope.

We further compared the effects of $\alpha_{2} \delta$-3 with those of the previously described $\alpha_{2} \delta$-1 subunit (Fig. 4, Table 1). The changes in gating-related channel characteristics elicited by both subunits were qualitatively similar, and in most cases the measurements (current density, voltage dependence of current activation and inactivation, and time course of current activation) were not significantly different. Both $\alpha_{2} \delta-1$ and -3 subunits accelerated the time course of current inactivation at a membrane potential of $+20 \mathrm{mV}$ by enhancing the proportion of the fast time constant, $\tau 1$. $\alpha_{2} \delta-3$ changed this constant from $273 \pm 24 \mathrm{msec}$ to $156 \pm 10$ msec. Surprisingly, $\alpha_{2} \delta-1$ significantly increased the value of the slow time constant $\tau 2$ from $1.16 \pm 0.08 \mathrm{sec}$ to $3.54 \pm 0.46 \mathrm{sec}$, but this effect was apparently overwhelmed by the effect of the increased proportion of the current inactivating with fast time constant $\tau 1$, with the result that the overall time course of inactivation was accelerated (Fig. $4 b$, inset). The effects of both $\alpha_{2} \delta-3$ and $\alpha_{2} \delta$ - 1 subunits on whole-cell current parameters, which reflect the gating of the $\alpha_{1 \mathrm{C}}$ channel, are virtually identical and they require the presence of $\beta$ (in this case $\beta 2$ a) to become prominent.

\section{Effects of the $\alpha_{2} \delta-3$ subunit on barium current through $\alpha_{1 E}$-type calcium channel}

Although both $\alpha_{1 \mathrm{C}}$ and $\alpha_{2} \delta-1$ subunits are fairly abundant in mammalian tissues, $\alpha_{1 \mathrm{E}}$ and $\alpha_{2} \delta-3$ are predominantly expressed in neuronal tissue. We therefore selected $\alpha_{1 \mathrm{E}}$ for studying the effects of $\alpha_{2} \delta$-3. For all experiments, $\beta 3$ subunit was coexpressed with $\alpha_{1 \mathrm{E}}$. This $\beta$ subunit was suggested to modulate the current through the $\alpha_{1 \mathrm{E}}$ channel (Ludwig et al., 1997). As with the $\alpha_{1 \mathrm{C}}$ channel, both $\alpha_{2} \delta-1$ and $\alpha_{2} \delta-3$ affected most of the gating-related parameters except for the time constant of current activation during membrane depolarization (Fig. 5, Table 1). In contrast to $\alpha_{1 \mathrm{C}} \beta 2 \mathrm{a}$ channel, the effects of $\alpha_{2} \delta-3$ and $\alpha_{2} \delta-1$ on the voltage dependence of current activation (Fig. $5 a$ ) and inactivation (Fig. $5 b)$ of $\alpha_{1 \mathrm{E}} \beta 3$ channel were significantly different. The $\alpha_{2} \delta-1$

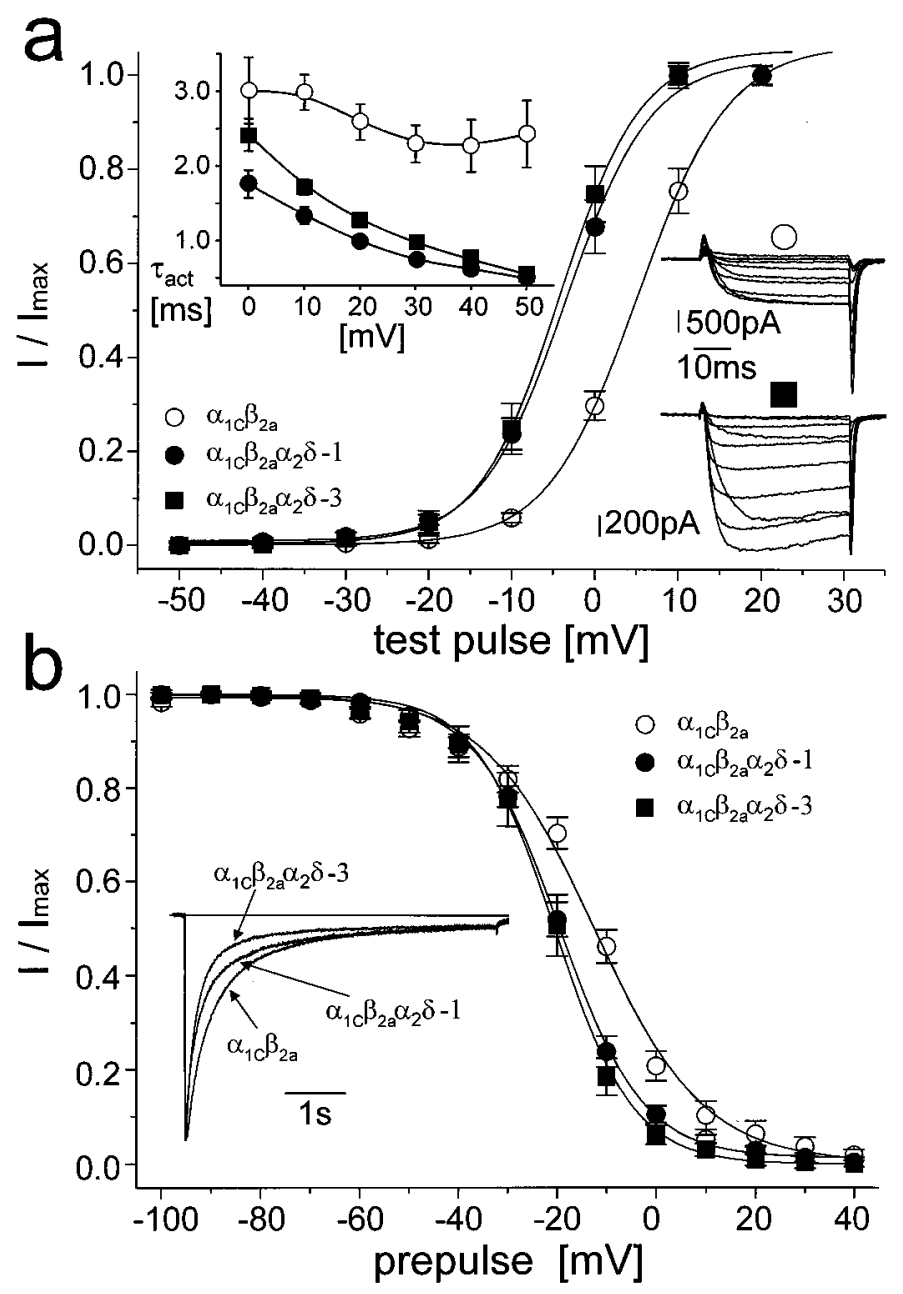

Figure 4. The $\alpha_{2} \delta$ subunit affects current through the $\alpha_{1 \mathrm{C}}$-type calcium channel. The $\alpha_{2} \delta-3$ subunit was coexpressed with $\alpha_{1 \mathrm{C}}$ and $\beta 2 \mathrm{a}$. For comparison, the current through cells coexpressing $\alpha_{2} \delta-1$ subunit was coanalyzed. $a$ shows the voltage dependence of current activation measured as the amplitude of current activated by a 40 -msec-long depolarizing pulse from a holding potential of $-80 \mathrm{mV}$ to voltages marked on the ordinate and normalized to the maximal amplitude. Each voltage dependence was fitted to the Boltzmann equation. Results of these fits are summarized in Table 1. The inset in the top left of $a$ shows voltage dependence of the kinetics of current activation. The ascending phase of the current time course was fitted to single exponential. The resulting time constants were averaged and plotted against corresponding membrane potentials. In both graphs, $\bigcirc$ represents the $\alpha_{1 \mathrm{c}} \beta 2 \mathrm{a}$ channel, $\bigcirc$ the $\alpha_{1 \mathrm{C}} \beta 2 \mathrm{a} \alpha_{2} \delta$-1 channel, and $\square$ the $\alpha_{1 \mathrm{C}} \beta 2 \mathrm{a} \alpha_{2} \delta$-3 channel. The inset in the right of $a$ illustrates a typical family of currents measured during a series of depolarizing pulses from the holding potential of $-80 \mathrm{mV}$ to membrane potentials ranging from -20 to $+70 \mathrm{mV}$ with a step of $+10 \mathrm{mV}$. $\bigcirc$, $\alpha_{1 \mathrm{C}} \beta 2 \mathrm{a}$ channel. The cell capacity was $83 \mathrm{pF}$, and the resulting maximal current density was approximately $-13 \mathrm{pA} / \mathrm{pF} ; \mathbf{\square}, \alpha_{1 \mathrm{C}} \beta 2 \mathrm{a} \alpha_{2} \delta-3$. The cell capacity was $31 \mathrm{pF}$, and the corresponding maximal current density was approximately $-41 \mathrm{pA} / \mathrm{pF} . b$ shows averaged steady-state inactivation curves measured from a holding potential of $-80 \mathrm{mV}$. Current was inactivated by a 5-sec-long prepulse to the potentials marked on the ordinate. This was followed by a 5-msec-long return to the holding potential and a 40-msec-long test pulse to the maximum of the currentvoltage relationship. Solid lines are fitted to the Boltzmann equation. The inset shows the time course of the current during a 5-sec-long depolarizing pulse to $+20 \mathrm{mV}$ with zero level indicated by a horizontal line. Currents shown are averaged time courses from 9 to 12 experiments scaled to the same amplitude. Individual measurements were fitted to the sum of two exponentials. Results of all fitting procedures are summarized in Table 1. Symbols are as in $a$. 


\begin{tabular}{|c|c|c|c|c|c|c|}
\hline & $\alpha_{1 \mathrm{C}} \beta 2 \mathrm{a}$ & $\alpha_{1 C} \beta 2 \mathrm{a} \alpha_{2} \delta-1$ & $\alpha_{1 \mathrm{C}} \beta 2 \mathrm{a} \alpha_{2} \delta-3$ & $\alpha_{1 \mathrm{E}} \beta 3$ & $\alpha_{1 \mathrm{E}} \beta 3 \alpha_{2} \delta-1$ & $\alpha_{1 \mathrm{E}} \beta 3 \alpha_{2} \delta-3$ \\
\hline$I_{\mathrm{Ba}}$ density $(\mathrm{pA} / \mathrm{pF})$ & $13.8 \pm 1.4(16)$ & $30.3 \pm 6.6^{*}(15)$ & $28.6 \pm 4.9 *(21)$ & $24.4 \pm 5.4(12)$ & $98.1 \pm 20.0^{* * *}(10)$ & $95.4 \pm 15.6^{* * *}(10)$ \\
\hline $\mathrm{V}_{0.5 \text { activ. }}(\mathrm{mV})$ & $+5.2 \pm 0.1(16)$ & $-5.0 \pm 0.6^{* * *}(13)$ & $-3.5 \pm 0.5^{* * *}(11)$ & $-13.0 \pm 1.1(10)$ & $-14.5 \pm 0.2(9)$ & $-20.1 \pm 0.7^{* * *, \text { aaa }}(11)$ \\
\hline $\mathrm{k}_{\text {activ }}$ & $5.4 \pm 0.1$ & $5.1 \pm 0.4$ & $5.1 \pm 0.4$ & $5.6 \pm 0.9$ & $3.7 \pm 0.1$ & $4.6 \pm 0.6$ \\
\hline $\mathrm{V}_{0.5 \text { inact. }}(\mathrm{mV})$ & $-12.5 \pm 0.9(9)$ & $-19.6 \pm .3^{* * *}(14)$ & $-20.5 \pm 0.4^{* * *}(8)$ & $-64.4 \pm 0.4(9)$ & $-69.7 \pm 0.4^{* * *}(11)$ & $-76.2 \pm 0.5^{* * * \text {, аaа }}(9)$ \\
\hline $\mathrm{k}_{\text {inact }}$ & $11.1 \pm 0.7$ & $8.5 \pm 0.2^{* * *}$ & $8.0 \pm 0.3^{* *}$ & $7.1 \pm 0.4$ & $8.4 \pm 0.4^{*}$ & $9.5 \pm 0.4^{* * *}$ \\
\hline A1 $(\%)$ & $61.1 \pm 3.9(12)$ & $73.7 \pm 4.5^{*}(11)$ & $78.1 \pm 2.6^{* *}(9)$ & $93.0 \pm 2.1(8)$ & $97.3 \pm 0.5^{*}(10)$ & $98.5 \pm 0.5^{* *}(10)$ \\
\hline$\tau 1(\mathrm{msec})$ & $273 \pm 24$ & $260 \pm 19$ & $156 \pm 10^{* * *}$, aaa & $31.9 \pm 5.7$ & $23.6 \pm 0.9$ & $24.1 \pm 1.7$ \\
\hline$\tau 2(\mathrm{sec})$ & $1.16 \pm 0.08$ & $3.54 \pm 0.46^{* * *}$ & $0.90 \pm 0.10^{\text {aaa }}$ & & & \\
\hline
\end{tabular}

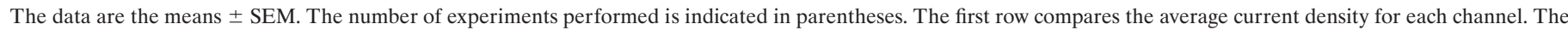

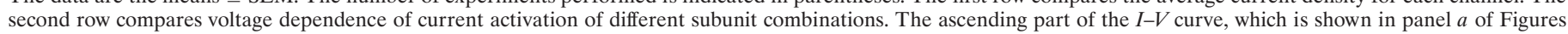

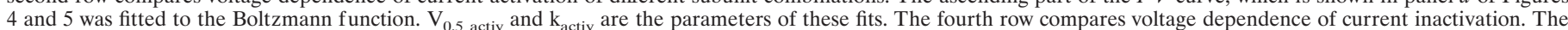

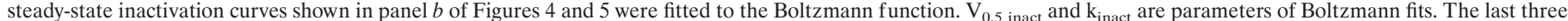

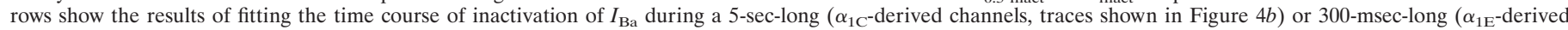

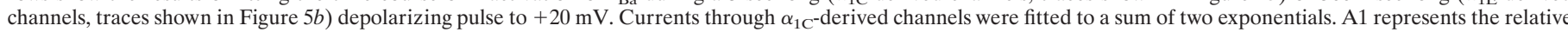

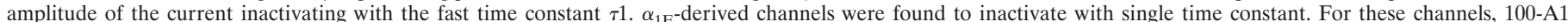

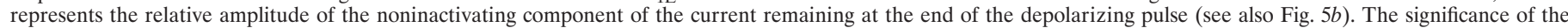

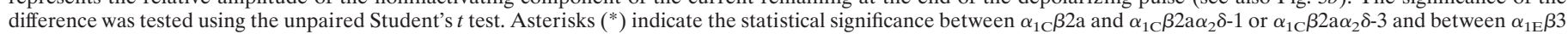
and $\alpha_{1 \mathrm{E}} \beta 3 \alpha_{2} \delta$-1 or $\alpha_{1 \mathrm{E}} \beta 3 \alpha_{2} \delta$-3. Significant difference between $\alpha_{1 \mathrm{C}} \beta 2 \mathrm{a} \alpha_{2} \delta-1$ and $\alpha_{1 \mathrm{C}} \beta 2 \mathrm{a} \alpha_{2} \delta-3$ and between $\alpha_{1 \mathrm{E}} \beta 3 \alpha_{2} \delta-1$ and $\alpha_{1 \mathrm{E}} \beta 3 \alpha_{2} \delta$-3 is marked by ( ${ }^{\mathrm{a}}$ ).

${ }^{*} p<0.05 ;{ }^{* *} p<0.01 ;{ }^{* * *} p<0.001$; ${ }^{\text {aaa }} p<0.001$.

subunit shifted both activation and steady-state inactivation curves in a hyperpolarizing direction, but the change in current activation was not statistically significant. In both curves, the shift evoked by $\alpha_{2} \delta-3$ was significantly larger (Table 1 ). In contrast, the effects of both $\alpha_{2} \delta$ s on the time course of current inactivation at a membrane potential of $+20 \mathrm{mV}$ were identical and restricted to diminution of the noninactivating part of the current (Table 1).

\section{DISCUSSION}

We present here the first account of the existence of multiple $\alpha_{2} \delta$ calcium channel subunits. The previously known $\alpha_{2} \delta$ we have named $\alpha_{2} \delta$ - 1 , and the new forms have been designated $\alpha_{2} \delta$-2 and $\alpha_{2} \delta-3$ based on their similarity to the original subunit. An amino acid alignment reveals that there is only a significant degree of homology in the core region of the $\alpha_{2}$ protein, whereas the $\delta$ proteins show identities only with respect to the cysteine residues. Despite the low degree of homology at the primary structure level between these forms, other features such as the number of glycosylation sites, cysteine residues, and hydrophobicity profiles are very similar. For these reasons we conclude that all three $\alpha_{2} \delta$ subunits are disulfide-linked proteins with similar higher order structures. The $\alpha_{2} \delta-1$ and -2 subunits are more ubiquitously expressed than $\alpha_{2} \delta-3$, which has only been identified in brain. Comparisons of the expression patterns of the 1 and 3 class $\alpha_{2} \delta$ subunits with $\alpha_{1}$ subunits in brain slices (Ludwig et al., 1997) do not indicate specific $\alpha_{1}-\alpha_{2} \delta$ combinations. We cannot exclude the possibility that $\alpha_{2} \delta-3$ also interacts with other ion channels or even other membrane proteins.

Functional coexpression of the $\alpha_{2} \delta$-1 subunit with various combinations of $\alpha_{1}$ and $\beta$ subunits results in an increase in the current densities or dihydropyridine (DHP)-binding sites (Singer et al., 1991; Welling et al., 1993; De Waard et al., 1995; Shistik et al., 1995; Bangalore et al., 1996; Gurnett et al., 1996; Felix et al., 1997; Parent et al., 1997; Jones et al., 1998), acceleration of current activation and inactivation (Singer et al., 1991; De Waard et al., 1995; Bangalore et al., 1996; Felix et al., 1997; Qin et al., 1998; Shirokov et al., 1998), and a shift of the current-voltage curve in a hyperpolarizing direction (Singer et al., 1991; Felix et al., 1997). Regardless of the $\alpha_{1}$ subunit used in this study, the $\alpha_{2} \delta-3$ subunit was found to increase the current density, which is in agreement with the results of these groups. In addition to this effect, coexpression of $\alpha_{2} \delta-3$ caused a shift of the voltage dependence of channel activation and inactivation in a hyperpolarizing direction and an acceleration in the kinetics of current inactivation.

When the results shown in Figures 4 and 5 are compared, it can be seen that $\alpha_{2} \delta$-1 caused a smaller shift in the voltage dependence of activation and inactivation of $\alpha_{1 \mathrm{E}} \beta 3$ as compared with the $\alpha_{1 C} \beta 2 \mathrm{a}$ channel. The effects of $\alpha_{2} \delta-3$ on the electrophysiological properties of $\alpha_{1 \mathrm{C}}$ coexpressed with $\beta 2 \mathrm{a}$ was found to be similar to those of $\alpha_{2} \delta$-1. In contrast, coexpression of $\alpha_{2} \delta$-3 with $\alpha_{1 \mathrm{E}}$ and $\beta 3$ produced more pronounced differences in the current characteristics associated with channel gating than the coexpression of $\alpha_{2} \delta-1$.

The mechanism whereby $\alpha_{2} \delta$ modulates the conductances of $\alpha_{1}$ is not clearly understood. The increase in density of current and DHP-binding sites can be explained by an improved targeting of expressed $\alpha_{1}$ subunit to the cell membrane and maturation of the channel complex (Shistik et al., 1995), which leads to an increased amount of charge moved during channel activation (Bangalore et al., 1996; Qin et al., 1998). It was suggested that the increase in current requires the presence of an intact $\alpha_{2}$ protein, whereas the shift of voltage-dependent activation and steady state inactivation as well as the acceleration of the inactivation kinetics are caused by the transmembrane $\delta$ protein (Felix et al., 1997). However, based on the amino acid similarity of the three subunit forms, it seems more likely that $\alpha_{2}$ harbors the relevant residues responsible for the observed effects on $\alpha_{1}$ and that the $\delta$ domain functions only as an membrane anchor for $\alpha_{2}$. This interpretation is further strengthened by the sequences of the $\delta$ proteins, which are not conserved.

These results, together with the brain-specific expression of $\alpha_{2} \delta$-3, suggest that the $\alpha_{2} \delta-3$ subunit may have a distinct physiological role in neuronal tissue. The $\alpha_{2} \delta$ protein has been implicated as the in vivo target for the antiepileptic drug gabapentin (Gee et al., 1996), which apparently inhibits calcium currents in isolated rat brain neurons (Stefani et al., 1998). It was proposed that gabapentin binds preferentially to the $\alpha_{2} \delta-1$ subunit. This is supported by evidence that the partial $\mathrm{N}$-terminal amino acid 

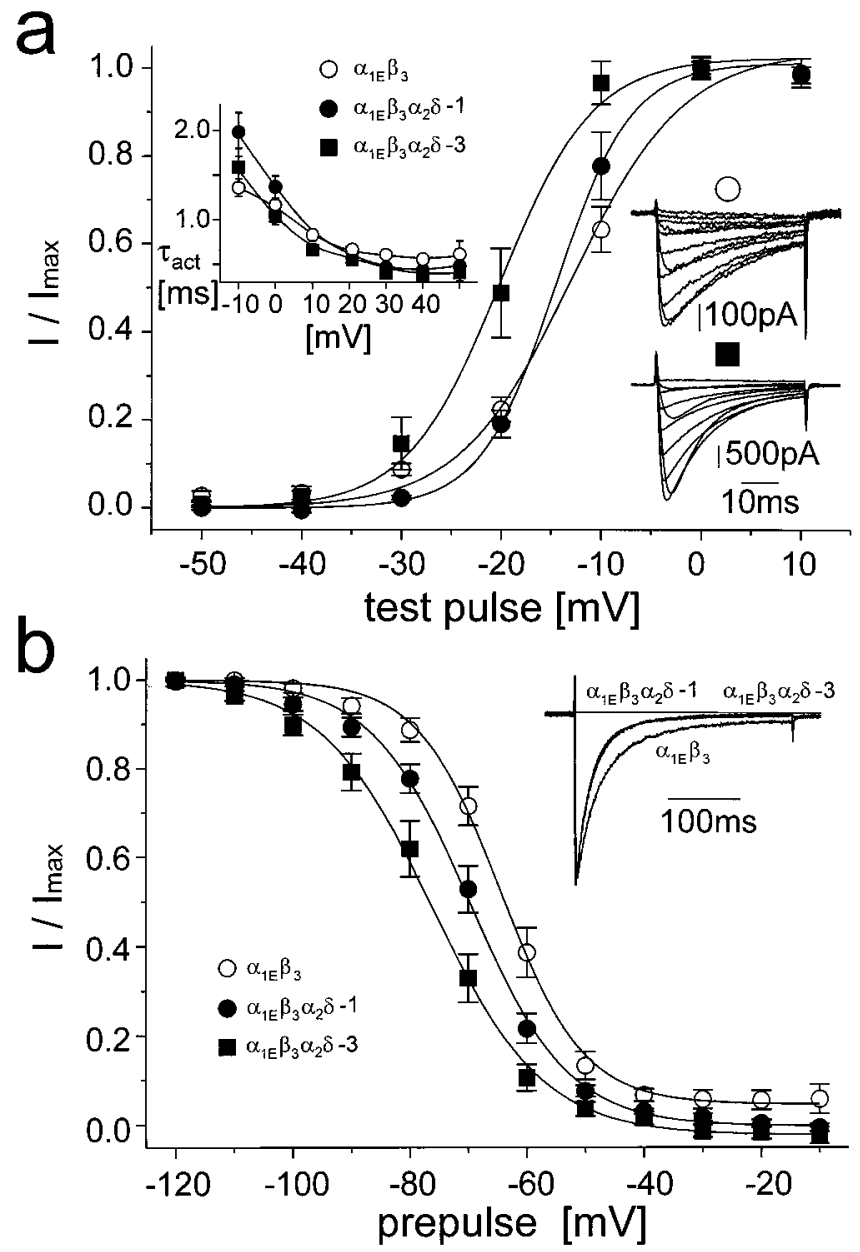

Figure 5. The $\alpha_{2} \delta$ subunit affects current through the $\alpha_{1 \mathrm{E}^{-t y p e} \text { calcium }}$ channel. Unless otherwise indicated, the voltage protocols used were the same as those described in the legend to Figure 4. $\bigcirc$ represents the $\alpha_{1 \mathrm{E}} \beta 3$ channel; - the $\alpha_{1 \mathrm{E}} \beta 3 \alpha_{2} \delta-1$ channel, and the $\alpha_{1 \mathrm{E}} \beta 3 \alpha_{2} \delta-3$ channel. Boltzmann fits of voltage dependencies of current activation are summarized in Table 1. The inset in the right of $a$ shows a typical family of currents measured during a series of depolarizing pulses from a holding potential of $-100 \mathrm{mV}$ to membrane potentials ranging from $-30 \mathrm{mV}$ to $+60 \mathrm{mV}$ with step of $+10 \mathrm{mV}$. $\bigcirc, \alpha_{1 \mathrm{E}} \beta 3$ channel, with a cell capacity of $19 \mathrm{pF}$ and a maximal current density of approximately $-34 \mathrm{pA} / \mathrm{pF} ; \mathbf{\square}$, $\alpha_{1 \mathrm{E}} \beta 3 \alpha_{2} \delta-3$ channel, with a capacity of $43 \mathrm{pF}$ and a maximal current density of approximately $-74 \mathrm{pA} / \mathrm{pF}$. $b$ shows the steady-state inactivation curve measured from a holding potential of $-100 \mathrm{mV}$ using a 5 -seclong conditioning pulse to membrane potentials marked on the ordinate. Solid lines represent Boltzmann fits. The insert illustrates the inactivation of $I_{\mathrm{Ba}}$ during a 300 -msec-long depolarizing pulse from a holding potential of $-100 \mathrm{mV}$ to $+20 \mathrm{mV}$ scaled to the same amplitude. Eight to 10 measurements were averaged for each channel type. The $\alpha_{1 \mathrm{E}} \beta 3 \alpha_{2} \delta-1$ and $\alpha_{1 \mathrm{E}} \beta 3 \alpha_{2} \delta$-3 current traces are indistinguishable from each other. Individual time courses of current inactivation were fitted to a single exponential with a small proportion of noninactivating current. Results of all fits are summarized in Table 1. Symbols are as in $a$.

sequence of the gabapentin-binding protein obtained from porcine brain membranes is identical with an aminoterminal peptide of $\alpha_{2} \delta-1$. This sequence is not present in classes 2 or 3. Further support for this postulate is that our mRNA in situ analysis of $\alpha_{2} \delta-1$ in brain showed the same distribution as that of gabapentinbinding sites (Taylor et al., 1998), which differs from that of $\alpha_{2} \delta-3$. For these reasons it is more likely that gabapentin targets the $\alpha_{2} \delta$ - 1 subunit. However, another study using a different purification procedure showed that there may be an additional gabapentin-binding protein in brain, which was detected with a polyclonal $\alpha_{2}$ antibody (Brown et al., 1998) and which could be another $\alpha_{2} \delta$ form. Further investigations need to be undertaken to elucidate the binding of gabapentin to the $\alpha_{2} \delta$ subunit.

\section{REFERENCES}

Angelotti T, Hofmann F (1996) Tissue-specific expression of splice variants of the mouse voltage-gated calcium channel $\alpha_{2} \delta$ subunit. FEBS Lett 397:331-337.

Bangalore R, Mehrke G, Gingrich K, Hofmann F, Kass RS (1996) Influence of L-type $\mathrm{Ca}$ channel $\alpha_{2} / \delta$-subunit on ionic and gating current in transiently transfected HEK 293 cells. Am J Physiol 270:H1521-H1528.

Bech-Hansen NT, Naylor MJ, Maybaum TA, Pearce WG, Koop B, Fishman GA, Mets M, Musarella MA, Boycott KM (1998) Loss-offunction mutations in a calcium-channel $\alpha_{1}$-subunit in Xp11.23 cause incomplete X-linked congenital stationary night blindness. Nat Genet 19:264-267.

Brickley K, Campbell V, Berrow N, Leach R, Norman RI, Wray D, Dolphin AC, Baldwin SA (1995) Use of site-directed antibodies to probe the topography of the $\alpha_{2}$ subunit of voltage-gated $\mathrm{Ca}^{2+}$ channels. FEBS Lett 364:129-133.

Brown JP, Dissanayke VUK, Briggs AR, Milic MR, Gee N (1998) Isolation of the $\left[{ }^{3} \mathrm{H}\right]$ gabapentin-binding protein $/ \alpha_{2} / \delta \mathrm{Ca}^{2+}$ channel subunit from porcine brain: development of a radioligand binding assay for $\alpha_{2} / \delta$ subunits using $\left[{ }^{3} \mathrm{H}\right]$ leucine. Anal Biochem 255:236-243.

Cribbs LL, Lee J-H, Yang J, Satin J, Zhang Y, Daud A, Barclay J, Williamson MP, Fox M, Rees M, Perez-Reyes E (1998) Cloning and characterization of $\alpha 1 \mathrm{H}$ from human heart, a member of the T-type $\mathrm{Ca}^{2+}$ channel gene family. Circ Res 83:103-109.

De Jongh KS, Warner C, Catterall WA (1990) Subunits of purified calcium channels. J Biol Chem 265:14738-14741.

De Waard M, Campbell KP (1995) Subunit regulation of the neuronal $\alpha_{1 \mathrm{~A}} \mathrm{Ca}^{2+}$ channel expressed in Xenopus oocytes. J Physiol (Lond) 485:619-634.

Eberst R, Dai S, Klugbauer S, Hofmann F (1997) Identification and functional characterization of a calcium channel gamma subunit. Pflügers Arch 433:633-637.

Ellis SB, Williams ME, Ways NR, Brenner R, Sharp AH, Leung AT, Campbell KP, McKenna E, Koch WJ, Hui A, Schwartz A, Harpold MM (1988) Sequence and expression of mRNAs encoding the $\alpha_{1}$ and $\alpha_{2}$ subunits of a DHP sensitive calcium channel. Science 241:1661-1664.

Felix R, Gurnett CA, De Waard M, Campbell KP (1997) Dissection of functional domains of the voltage-dependent $\mathrm{Ca}^{2+}$ channel $\alpha_{2} \delta$ subunit. J Neurosci 17:6884-6891.

Gee NS, Brown JP, Dissanayake VUK, Offord J, Thurlow R, Woodruff GN (1996) The novel anticonvulsant drug, gabapentin (neurontin), binds to the $\alpha_{2} \delta$ subunit of a calcium channel. J Biol Chem 271:5768-5776.

Gurnett CA, De Waard M, Campbell KP (1996) Dual function of the voltage-dependent $\mathrm{Ca}^{2+} \alpha_{2} \delta$ subunit in current stimulation and subunit interaction. Neuron 16:431-440.

Hofmann F, Biel M, Flockerzi V (1994) Molecular basis for $\mathrm{Ca}^{2+}$ channel diversity. Annu Rev Neurosci 17:399-418.

Jay SD, Sharp AH, Kahl SD, Vedvick TS, Harpold MM, Campbell KP (1991) Structural characterization of the dihydropyridine-sensitive calcium channel $\alpha_{2}$-subunit and the associated $\delta$ peptides. J Biol Chem 266:3287-3293.

Jones LP, Wei S-K, Yue DT (1998) Mechanisms of auxiliary subunit modulation of neuronal $\alpha_{1 \mathrm{E}}$ calcium channels. J Gen Physiol 112:125-143.

Kyte J, Doolittle RF (1982) A simple method for displaying the hydropathic character of a protein. J Mol Biol 157:105-132.

Letts VA, Felix R, Biddlecome GH, Arikkath J, Mahaffey CL, Valenzuela A, Bartlett FS, Mori Y, Campbell KP, Frankel WN (1998) The mouse stargazer gene encodes a neuronal $\mathrm{Ca}^{2+}$-channel $\gamma$ subunit. Nat Genet 19:340-347.

Ludwig A, Flockerzi V, Hofmann F (1997) Regional expression and cellular localization of the $\alpha_{1}$ and $\beta$ subunit of high voltage-activated calcium channels in rat brain. J Neurosci 17:1339-1349.

Parent L, Schneider T, Moore CP, Talwar D (1997) Subunit regulation of the human brain $\alpha_{1 \mathrm{E}}$ calcium channel. J Membr Biol 160:127-140.

Perez-Reyes E, Cribbs LL, Daud A, Lacerda AE, Barclay J, Williamson MP, Fox M, Rees M, Lee J-H (1998) Molecular characterization of a 
neuronal low-voltage-activated T-type calcium channel. Nature 391:896-899.

Qin N, Olcese R, Stefani E, Birnbaumer L (1998) Modulation of human neuronal $\alpha_{1 \mathrm{E}}$-type calcium channel by $\alpha_{2} \delta$-subunit. Am J Physiol 274:C1324-C1331.

Schuster A, Lacinová L, Klugbauer N, Ito H, Birnbaumer L, Hofmann F (1996) The IV26 segment of the L-type calcium channel is critical for the action of dihydropyridines and phenylalkylamines. EMBO J 15:2365-2370.

Shirokov R, Ferreira G, Yi J, Ríos E (1998) Inactivation of gating currents of L-type calcium channels. Specific role of the $\alpha 2 \delta$ subunit. J Gen Physiol 111:807-823.

Shistik E, Ivanina T, Puri T, Hosey M, Dascal N (1995) $\mathrm{Ca}^{2+}$ current enhancement by $\alpha 2 / \delta$ and $\beta$ subunits in Xenopus oocytes: contribution of changes in channel gating and $\alpha 1$ protein level. J Physiol (Lond) 489:55-62.

Singer D, Biel M, Lotan I, Flockerzi V, Hofmann F, Dascal N (1991) The roles of the subunits in the function of the calcium channel. Science 253:1553-1557.
Stefani A, Spadoni F, Bernardi G (1998) Gabapentin inhibits calcium currents in isolated rat brain neurons. Neuropharmacology 37:83-91.

Strom TM, Nyakatura G, Apfelstedt-Sylla E, Hellebrand H, Lorenz B, Weber BH, Wutz K, Gutwillinger N, Ruther K, Drescher B, Sauer C, Zrenner E, Meitinger T, Rosenthal A, Meindl A (1998) An L-type calcium-channel gene mutated in incomplete X-linked congenital stationary night blindness. Nat Genet 19:260-263.

Taylor CP, Gee NS, Su T-Z, Kocsis JD, Welty DF, Brown JP, Dooley DJ, Boden P, Singh L (1998) A summary of mechanistic hypotheses of gabapentin pharmacology. Epilepsy Res 29:233-249.

Welling A, Bosse E, Cavalié A, Bottlender G, Ludwig A, Nastainczyk W, Flockerzi V, Hofmann F (1993) Stable co-expression of calcium channel, $\alpha_{1}, \beta$ and $\alpha_{2} / \delta$ subunits in a somatic cell line. J Physiol (Lond) 471:749-765.

Wiser O, Trus M, Tobi D, Halevi S, Giladi E, Atlas D (1996) The $\alpha_{2} / \delta$ subunit of voltage sensitive $\mathrm{Ca}^{2+}$ channels is a single transmembrane extracellular protein which is involved in regulated secretion. FEBS Lett 379:15-20. 